\title{
Linguistic Landscape and Minority Languages
}

\author{
Jasone Cenoz \\ University of the Basque Country, Donostia-San Sebastian, Spain \\ Durk Gorter \\ Fryske Akademy/Universiteit van Amsterdam, Amsterdam, \\ The Netherlands
}

This paper focuses on the linguistic landscape of two streets in two multilingual cities in Friesland (Netherlands) and the Basque Country (Spain) where a minority language is spoken, Basque or Frisian. The paper analyses the use of the minority language (Basque or Frisian), the state language (Spanish or Dutch) and English as an international language on language signs. It compares the use of these languages as related to the differences in language policy regarding the minority language in these two settings and to the spread of English in Europe. The data include over 975 pictures of language signs that were analysed so as to determine the number of languages used, the languages on the signs and the characteristics of bilingual and multilingual signs. The findings indicate that the linguistic landscape is related to the official language policy regarding minority languages and that there are important differences between the two settings.

Keywords: minority languages, linguistic landscape, English, Frisian, Basque

\section{Introduction: The Study of the Linguistic Landscape}

Multilingualism is a common phenomenon, which can be studied from different perspectives including the use of languages in the sociolinguistic context. One of the possibilities is to analyse languages in context by focusing on the written information that is available on language signs in a specific area. This perspective is known as the study of the linguistic landscape, which has been defined as follows:

The language of public road signs, advertising billboards, street names, place names, commercial shop signs, and public signs on government buildings combines to form the linguistic landscape of a given territory, region, or urban agglomeration. The linguistic landscape of a territory can serve two basic functions: an informational function and a symbolic function. (Landry \& Bourhis, 1997: 25)

This paper focuses on the relationship between linguistic landscape and the sociolinguistic context. This relationship is bidirectional. On the one hand, the linguistic landscape reflects the relative power and status of the different languages in a specific sociolinguistic context. In this sense it is the product of a specific situation and it can be considered as an additional source of information about the sociolinguistic context along with censuses, surveys or interviews. The majority language of a language community is more likely to 
be used more often in place names or commercial signs while the minority language or languages will not be as common (see for example Ramamoorthy, 2002; Xiao, 1998). On the other hand, the linguistic landscape contributes to the construction of the sociolinguistic context because people process the visual information that comes to them, and the language in which signs are written can certainly influence their perception of the status of the different languages and even affect their own linguistic behaviour. The linguistic landscape or parts of the linguistic landscape can have an influence on language use.

The study of the linguistic landscape is particularly interesting in bilingual and multilingual contexts. The linguistic landscape can provide information about the sociolinguistic context and the use of the different languages in language signs can be compared to the official policy of the region and to the use of the language as reported in surveys. The study of the linguistic landscape can also be interesting because it can provide information on the differences between the official language policy that can be reflected in topdown signs such as street names or names of official buildings and the impact of that policy on individuals as reflected in bottom-up signs such as shop names or street posters.

This paper focuses on a comparison of the use of different languages in the linguistic landscape of one central shopping street in Donostia-San Sebastian in the Basque Country and one similar street in Ljouwert-Leeuwarden in Friesland, The Netherlands.

The study of the linguistic landscape of a single street was also reported by Rosenbaum et al. (1977). This study analysed sign counts along with transactions, planted encounters and interviews in Keren Kayemet Street in Jerusalem. The study of language signs is limited to analysing the use of the Roman and the Hebrew script on the signs. The results of the analysis indicate that the Roman script is more common on bottom-up than top-down signs and show the differences between official language policy supporting the use of Hebrew-only signs and the most common use of other languages (mainly English) in commercial signs.

The sociolinguistic context in which our study was carried out is also based on one street in each city but presents important differences when compared to the study reported by Rosenbaum et al . (1977): (1) the two languages (Basque/ Spanish or Frisian/Dutch) are official languages; (2) there are no specific districts in the two cities (Donostia, Ljouwert) which can be considered Basque/Frisian or Spanish/Dutch in the sense of being inhabited predominantly by Basque/Frisian or Spanish/Dutch speakers.

\section{Background Information on Both Language Groups}

\section{Friesland}

Friesland is one of the 12 provinces of the Netherlands. The province is located in the Northwest. Its territory has a surface of $3360 \mathrm{~km}^{2}$ (a bit more than Luxemburg). Friesland has a population of 643,000 (2004), which is equal to 190 inhabitants per $\mathrm{km}^{2}$ (cf. the Netherlands: 16.0 million inhabitants; 470 per $\mathrm{km}^{2}$ ). The capital is Leeuwarden (Fr. Ljouwert), which has some 91,000 
inhabitants. A dense pattern of over 300 villages with only a few larger towns is typical for Friesland; the tiniest villages may have less than 25 inhabitants.

Approximately $94 \%$ of the population can understand Frisian, $74 \%$ can speak Frisian, $65 \%$ can read it and $17 \%$ can write the language (Gorter \& Jonkman, 1995). Over the last 25 years or so, a slow decline has been observed in speaking proficiency and some increase in writing abilities. There is, however, an increased language shift among the younger generations towards Dutch as a first language (Gorter, 2005).

The use of Frisian shows an uneven pattern over differing social domains. In the domains of the family, work and the village community Frisian demonstrates a relatively strong position, where still a small majority of the population habitually uses Frisian. In the more formal domains of education, media, public administration and law, Dutch dominates (Gorter et al., 2001).

The Frisian language has been officially recognised as the second language of the Netherlands. That formal recognition has entailed moderate promotion of the language by the authorities of the state and the province. Certain provisions for the use of Frisian have been made in a process of legal codification. There is general political agreement that the government has a duty in protecting and promoting Frisian.

However, the policy plans have a noncommittal character and they have hardly been implemented (Gorter, 2001). The power of the taken-forgrantedness of Dutch appears stronger than the formal operation of the language policy intentions.

\section{Basque Country}

The Basque Country extends over an area of approximately $20,700 \mathrm{~km}^{2}$ in the North of Spain and the South of France at the Atlantic border. It covers the Basque Autonomous Community, the region of Navarre and Iparralde. The total Basque population is approximately three million, 91\% being Spanish citizens. The percentage of bilinguals (Basque-Spanish or Basque-French) for the whole of the Basque Country is $22 \%$ and $14.5 \%$ are passive bilingual (only comprehension skills in Basque and limited production). With a few exceptions, the rest of the population is monolingual Spanish or French. According to a recent survey (Euskararen Jarraipena, 2003), the number of bilinguals in the Basque Autonomous Community, where the city of Donostia-San Sebastian is located, is increasing and currently comprises $29 \%$ of the population. The number of bilinguals (Basque-Spanish) in the city of Donostia-San Sebastian is higher, 33\% of the population. San Sebastian has approximately 180,000 inhabitants.

Basque and Spanish have been official languages in the Basque Autonomous Community since 1979. The Basque Government has actively encouraged the use of Basque as the language of instruction and at present $83 \%$ of kindergarten/primary schoolchildren and $65 \%$ of secondary schoolchildren have this language as a language of instruction (see also Cenoz, 2001, 2005). Apart from promoting the use of Basque in education, the Basque Government has created specific institutions to teach and promote the use of Basque in other sectors such as government services, the media or private companies. 
This policy has had some effect in restoring the status of Basque and reversing language shift, but in spite of the support given by the Basque Government, Basque is still a language at risk and according to the 2001 survey, only $11.9 \%$ of the population use it more than Spanish and $6.8 \%$ of the population consider that they use Basque as much as Spanish (Euskararen Jarraipena III, 2003).

\section{The Use of English in Friesland and the Basque Country}

The increasing spread of English in Europe can also be seen both in Friesland and in the Basque Country. In both regions English is becoming part of the linguistic landscape. English is taught at schools in Friesland from the end of primary school (10 year olds), whereas in the Basque Country, English is taught in most schools from the age of four. In Friesland the self-assessed ability in English is rather high as over 70\% rates its knowledge of English as 'good' or 'very good' (Eurobarometer, 2001). The knowledge and use of English in the Basque Country is more limited as compared to other regions in Central and Northern Europe (see also Cenoz \& Jessner, 2000).

The use of English in commercial signs does not seem to be intended to transmit factual information but is used for its connotational value. As Piller (2001, 2003) points out, the audience can recognise that the message is in English and this activates values such as international orientation, future orientation, success, sophistication or fun orientation.

\section{Research Questions}

This paper analyses the differences between Friesland and the Basque Country, mainly in an urban context. The study of the linguistic landscape is very interesting in the context of minority languages such as are in use in the Basque Country and in Friesland in order to see the relative use of the different languages (Basque, Spanish, English in the first case and Frisian, Dutch and English in the second) and the differences between official top-down and bottom-up signs and the use of English.

The specific research questions of this study are the following:

(1) Which are the languages displayed in the linguistic landscape of Donostia-San Sebastian and Ljouwert-Leeuwarden respectively, and their relative weight?

(2) What are bilingual and multilingual signs like?

\section{Methodology}

The corpus of this study includes a complete inventory of the linguistic landscape of just one street in the Basque Country and one street in Friesland, based on the example of the study of the use of English in Keren Kayemet Street in Jerusalem, Israel (Rosenbaum et al., 1977). The streets selected for this study were 'Bulevar-Boulevard', one of the central shopping streets of Donostia-San Sebastian and 'Nijstêd-Nieuwestad' in the centre of 
Ljouwert-Leeuwarden. Both of these streets have a length of approximately $600 \mathrm{~m}$.

In contrast to the study by Rosenbaum et al. (1977), our approach involved taking digital pictures of all texts we saw on the street. We took a total of 975 pictures. In many cases we took more than one picture of the same text or sign or combination of signs. In the end we distinguished 207 different units, 104 in Donostia and 103 in Ljouwert.

The codification of the different pictures presents some difficulties and some decisions had to be taken. One of the most important decisions is to establish the unit of analysis. After excluding other possibilities it was decided that in the case of shops and other businesses each establishment but not each sign was the unit of analysis, that is, it was considered 'one single sign' for the analysis. So, when a bank or a shop had its name on the front but also a number of advertising posters on the windows it was considered one sign (or one unit). This decision is based on the fact that all the signs in one establishment, even if they are in different languages, have been the result of the languages used by the same company give an overall impression because each text belongs to a larger whole instead of being clearly separate. Therefore, we went to great lengths to even include in the pictures also very small texts such as those on the side of a sunshade or a safety-rack with the brand name which would hardly be noticed by someone passing by, but these texts were included in the larger whole of the establishment as unit of analysis. In spite of the decisions taken for the codification there is a degree of arbitrariness involved in the process but in coding them independently of each other both authors agreed in over $98 \%$ of cases.

We developed a coding scheme that included 16 variables (based on Ben-Rafael et al., 2001; this volume) and we will refer to the most general ones in this paper. These include the type of sign, branch, the number of languages on the sign, the languages on the sign, top-down versus bottom up signs, first language on bilingual signs, signs of the languages on bilingual signs and type of font on bilingual signs.

The two streets are commercial streets and they have different types of shops: clothing (47 in Ljouwert; 32 in Donostia), books (1 in Ljouwert; 1 in Donostia), food (1 in Ljouwert; 6 in Donostia), furniture (7 in Ljouwert; 1 in Donostia), computers (2 in Ljouwert; 2 in Donostia), etc. By far most of them are independent small shops (73\% in Ljouwert; $78 \%$ in Donostia) and few belong to a national or international chain. There is the category of 'other' into which $3 \%$ in Ljouwert and $12 \%$ in Donostia of the remaining signs were classified. These include graffiti, commercial and noncommercial posters.

\section{Results}

This section shows the results of the study, which have been arranged so as to answer the two research questions: (1) which are the languages displayed? and (2) what are the characteristics of bilingual or multilingual signs? 


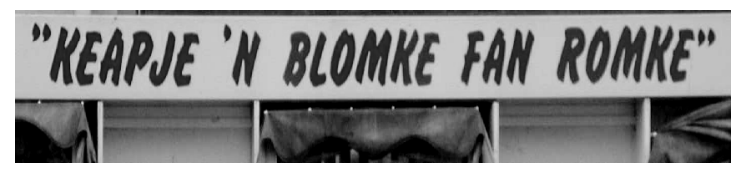

Picture A Monolingual Frisian text (translation: 'Buy a flower from Romke')

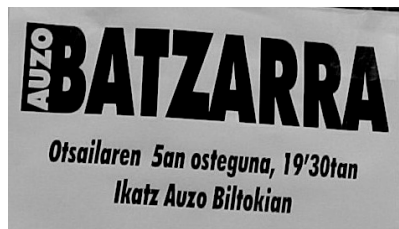

Picture B Monolingual Basque text (translation: Community meeting on the 5th of february, Thursday at 19.30 at the Ikatz community meeting place)

\section{Research question 1: Languages displayed}

The first question about languages displayed concerns the number of languages used in each unit of analysis (sign). Table 1 gives the results. Almost two thirds of the signs (64\%) in Ljouwert only have one language, but $36 \%$ have two and $8 \%$ have three or more. So in Ljouwert most of the signs are monolingual. However, the overall picture in Donostia is quite different. Less than half (45\%) of the signs are monolingual and almost as many $(37 \%)$ have two languages and almost one in five (19\%) have three or more languages. The overall impression in terms of bi- and multilingualism in Donostia is different from Ljouwert.

The next question is about which languages are being used and the results are given in Table 2. We are dealing with a minority language, either Frisian or Basque, with a dominant (state) language Dutch and Spanish and with English as an international language that has gained a certain presence in both contexts. Other international languages such as French or German take a modest place.

We can compare Ljouwert and Donostia for the place given to the minority language, the dominant language and English, respectively.

For the minority language we observe a substantial difference between Frisian and Basque. Frisian only appears on its own in 3\% of cases and has a small presence as well in Frisian-Dutch bilingual signs and no presence in multilingual signs at all (see Picture A). The minimal presence of Frisian as a

Table 1 Number of languages on the sign (percentages)

\begin{tabular}{|l|c|c|}
\hline Number of languages & Ljouwert & Donostia \\
\hline 1 & 64 & 45 \\
\hline 2 & 36 & 37 \\
\hline 3 & 6 & 12 \\
\hline $4+$ & 2 & 7 \\
\hline$n$ & 103 & 104 \\
\hline
\end{tabular}


Table 2 Language on sign (percentages)

\begin{tabular}{|l|c|c|}
\hline & Ljouwert & Donostia \\
\hline Frisian/Basque & 3 & 12 \\
\hline Dutch/Spanish & 53 & 36 \\
\hline English & 6 & 4 \\
\hline Frisian \& Dutch/Basque \& Spanish & 2 & 22 \\
\hline Dutch \& English/Spanish \& English & 31 & 6 \\
\hline Basque \& English & - & 2 \\
\hline Basque, Spanish \& English & - & 10 \\
\hline Other combinations \& languages & 5 & 8 \\
\hline$n$ & 103 & 104 \\
\hline
\end{tabular}

written language on the signs reflects the modest place of the written language in society in general. Frisian is predominantly a spoken language (over half the population can speak Frisian) and the amount of documents, forms, books, journals, etc in Frisian is rather minimal when compared to Dutch (Gorter, 2001).

On the contrary, Basque has a stronger presence in monolingual signs with about one in every eight signs: $12 \%$ (see Picture B). When we take all signs together where there is Basque involved the total comprises half of all the signs (12\% monolingual $+22 \%$ bilingual Basque-Spanish $+2 \%$ Basque-English $+10 \%$ Basque-Spanish-English + a few of the other combinations also involve Basque: together over 50\%). We know that Basque is spoken by about one third of the population, but as a written language its importance is clearly shown in the linguistic landscape. The acceptance of Basque as a written language is high in all sectors of society. Here Ljouwert (Friesland) and Donostia (Basque Country) differ to a large degree.

When we turn to the socially dominant language in each case, that is Dutch in Ljouwert and Spanish in Donostia, we also see some differences, but they seem not as important. In Ljouwert Dutch is present in $91 \%$ of all signs, either monolingual Dutch in over half of the signs (53\%) or bilingual or multilingual signs $(31 \%+2 \%+5 \%)$. Dutch is not present in $9 \%$ of the signs (3\% Frisian, $6 \%$ English). Therefore, Dutch is obviously the dominant language in the linguistic landscape of Ljouwert. Spanish is the most common language in Donostia with over one third of all signs in Spanish only (36\%). If we add to

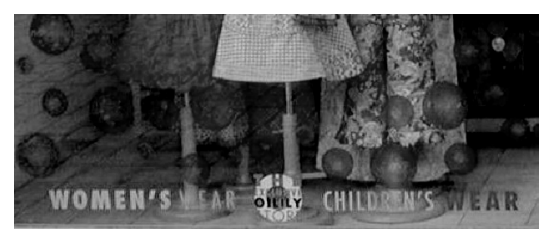

Picture C Monolingual English text in a clothing shop 
this figure the bilingual and trilingual signs that also have Spanish, we see that Spanish can be found on $82 \%$ of the signs and in that sense Spanish is dominating the linguistic landscape $(22 \%+6 \%+10 \%+8 \%)$.

The difference between Ljouwert and Donostia as far as English is concerned in monolingual signs is small with $6 \%$ and $4 \%$ respectively (see Picture $\mathrm{C}$ for a monolingual English sign in Ljouwert). However, when we add all the signs with a presence of English on it then we see that English is present in $37 \%$ of all signs in Ljouwert $(6 \%+31 \%)$ and only in $28 \%$ of all signs in Donostia $(4 \%+6 \%+2 \%+10 \%+6 \%$ of the combinations). Other foreign languages have a very limited presence, with some signs including some words in French or German.

We can conclude that Dutch and Spanish are the dominant languages and the linguistic landscape reflects this fact. Basque as a minority language also has a clear presence, whereas Frisian is hardly to be seen. English is the most important compared to other 'foreign' languages. English is stronger in Ljouwert than in Donostia.

The linguistic landscape seems to reflect the general sociolinguistic situation as well as the intensity of language policies for the minority language.

\section{Research question 2: The characteristics of bilingual and multilingual signs}

In this section we will have a closer look at the composition of the multilingual signs. Some examples of these signs can be seen in Pictures D, E and F. Picture D was taken in Ljouwert and it is in English and Dutch. Pictures $\mathrm{E}$ and $\mathrm{F}$ are from Donostia and the both have Basque and Spanish but Picture F also has four more languages: English, German, Italian and French. We can analyse the bilingual signs according to the place the languages occupy on these signs. The way the languages are displayed vis-à-vis each other will give us further information on the relative importance given to each language. We will first look at the first language on the sign, then the size of the lettering of the language and finally the fonts of the letters used.

\section{First language on bi/multilingual signs}

Table 3 The first/most prominent language on bilingual signs (percentages)

\begin{tabular}{|l|c|c|}
\hline & Ljouwert & Donostia \\
\hline Frisian/Basque & 2 & 28 \\
\hline Dutch/Spanish & 77 & 67 \\
\hline English & 20 & 5 \\
\hline$n$ & 52 & 61 \\
\hline
\end{tabular}

The first characteristic of the signs analysed was the order of languages in the bi/multilingual signs. The results corresponding to the first language on the sign (or the clearly most prominent one) are given in Table 3. The bilingual 


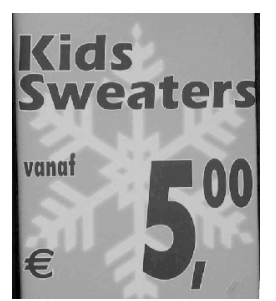

Picture D Dutch-English text (translation: vanaf $=$ from)

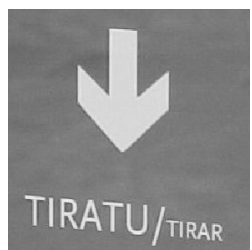

Picture E Bilingual Basque-Spanish text (Basque bigger; translation: put)

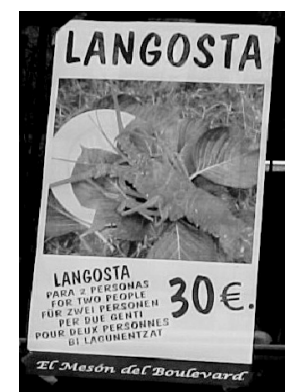

Picture F Multilingual text in 6 languages (Spanish, English, German, Italian, French and Basque)

signs in both cities clearly differ from each other again when it comes to place of the minority language as the first language on bilingual signs. Frisian is the first language in only $2 \%$, but Basque is used in $28 \%$ of all cases. For the international language English it is almost the reverse: one in every five bilingual signs in Ljouwert has English as the first language, whereas English plays a much less prominent role in Donostia. Both majority languages Dutch and Spanish do not differ so much, both are dominating most bilingual signs, although Dutch takes even more prominence.

\section{Size of text in bi/multilingual signs}

The second step was to analyse the size of the fonts of each language in all the bi/multilingual signs. The results are given in Table 4 . In the case of Ljouwert most commonly the size of the texts on bi/multilingual signs are not the same, in most cases the majority language is bigger and in just a few cases the minority language is bigger.

The results for Donostia show more variety. In over half of the cases the majority language Spanish takes the most prominent place in terms of size, but also a substantial part is where Basque takes prominence. English is again the language that takes a modest place. 
Table 4 Size of languages on bi/multilingual signs (percentages)

\begin{tabular}{|l|c|c|}
\hline & Ljouwert & Donostia \\
\hline All the same & 8 & 20 \\
\hline Minority bigger & 3 & 14 \\
\hline Majority bigger & 47 & 58 \\
\hline Majority + minority bigger & - & - \\
\hline Majority + foreign bigger & 42 & 3 \\
\hline
\end{tabular}

\section{Type of font on bi/multilingual signs}

Table 5 Type of font on bi/multilingual signs (percentages)

\begin{tabular}{|l|c|c||}
\hline \hline Type of font & Ljouwert & Donostia \\
\hline Same all languages & 6 & 22 \\
\hline Different & 94 & 78 \\
\hline$n$ & 36 & 59 \\
\hline
\end{tabular}

The next step is to look at the type of font used for the textual display of the language. The results indicating if the fonts are the same or not in the different languages are given in Table 5. The difference between Ljouwert and Donostia is obvious when it comes to the type of font. In the case of signs in Ljouwert, most signs in two or more languages have different fonts. In the case of Donostia it is quite common $(22 \%)$ to have the same fonts in different languages.

\section{Amount of information}

Another characteristic of bi/multilingual signs that was analysed was the amount of information given in each of the languages. The results are given in

Table 6 Amount of information given on bi/multilingual signs (percentages)

\begin{tabular}{|l|c|c||}
\hline Information & Ljouwert & Donostia \\
\hline Same all languages & 6 & 15 \\
\hline Minority more & 3 & 10 \\
\hline Majority more & 72 & 63 \\
\hline Majority + minority more & - & 9 \\
\hline Foreign more & 17 & 3 \\
\hline Ambiguous & 3 & - \\
\hline$n$ & 36 & 59 \\
\hline
\end{tabular}


Table 6. Again we observe an important difference between Ljouwert and Donostia when it comes to the amount of information provided.

In the case of Ljouwert, signs contain more information in Dutch than in other languages. The same trend can be observed in Donostia, but it is not as prominent. The information is repeated completely in one or more languages in a few cases. This repetition seldom happens in the case of Ljouwert but is more common in Donostia where it happens in one in every six bilingual signs. In a number of cases the information given in the foreign language, English, is more extensive than the information in the majority language Dutch. This hardly happens in Donostia.

\section{Translation in bi/multilingual signs}

A final characteristic included in this study was again the comparison of the information given in the different languages but focusing on the use of translation in the signs. The results are given in Table 7. In Ljouwert there is hardly any translation but there are a number of signs which have been classified as ambiguous because the text is in one language but it is not clear which language it is because of the similarities between Dutch, Frisian and English. The linguistic distance between Basque, Spanish and English avoids ambiguity regarding the languages in the signs in Donostia.

There is no official policy of dual language use in Friesland. The official policy has been for many years an 'either-or' system for language choice. Official government documents are published either in Dutch, or in Frisian. Using both Frisian and Dutch side by side in literal translation was seen as superfluous, because all inhabitants of Friesland were supposed to be able to read both languages. As mentioned above, only $67 \%$ of the population is able to read Frisian and in practice almost all official documents are published in Dutch, with the exception of a few documents in the field of culture.

The linguistic distance between Spanish and Basque is much larger and the official policy has been from the beginning to make all kinds of documents available in both languages. Even though the whole population can read Spanish, the translation is not considered superfluous. The official policy is reflected in the linguistic landscape not only in the case of official top-down signs but also in many cases when bottom-up signs are considered. In fact, the results indicate that in most cases we see some form of translation and only a bit less than one third of the signs have no translation. About $10 \%$ of the texts

Table 7 Translation of texts in bi/multilingual signs

\begin{tabular}{|l|c|c|}
\hline \hline Translation & Ljouwert & Donostia \\
\hline Word to word & - & 10 \\
\hline No translation & 89 & 31 \\
\hline Partial translation & - & 56 \\
\hline Ambiguous & 11 & - \\
\hline$n$ & 36 & 59 \\
\hline
\end{tabular}


are word-to-word translations, and most of them are official texts. In the case of partial translations the picture is less clear.

\section{Conclusions}

When we try to summarise the order of dominance of the three languages, we see that Dutch is by far the most prominent language in the linguistic landscape of Ljouwert, followed by English as the second language and in the third place comes Frisian with a marginal presence. The order of languages in Donostia is Spanish first, Basque second and English third.

In both cities the majority language (Dutch or Spanish) is also more prominent in the signs regarding the size of the fonts, the position of the text as compared to other languages and the information given in the text.

The main differences between the two cities are related to the use of the minority language in language signs. There are more signs in Basque than in Frisian and this difference shows the effect of a strong language policy to protect the minority language on the linguistic landscape. The effect of this policy is not only reflected in top-down signs designed by the Town Hall or the County Hall but also in commercial signs. It is also interesting to observe that the same information is given in both official languages quite often in Donostia but not in Ljouwert. It is interesting to observe that the use of Basque in writing in language signs is much higher than the use of Frisian while Frisian is stronger as a language of oral communication than Basque. These findings clearly indicate the differences in language policy between the two contexts and how the active policy to promote Basque in the Basque Country has an important effect on the visibility of the Basque language both in topdown and bottom-up signs.

Another important finding of this study is the spread of English in the signs analysed in this study (see also Bhatia, 1992; Martin, 2002; Takashi, 1990). There are two interesting points to be mentioned as related to this spread. English is clearly the language of international communication and other 'strong' languages such as German and French are only marginally found in the data even though Germany is close to Ljouwert and France very close to Donostia. The use of English is more prominent in Ljouwert than in Donostia but its use in $28 \%$ of the signs of a main shopping street in Donostia shows that English is no longer marginal. Donostia is more touristic than Ljouwert and our data may not reflect the use of English in other Southern European cities but they show the shift from French to English as the language of international communication.

This study shows that the linguistic landscape has both an information and a symbolic function (Landry \& Bourhis, 1997, see also Ben-Rafael et al., 2001). The informative function shown in the signs in the different languages indicates the language to be used in communication at shops and other businesses and also reflects the relative power of the different languages. The use of the different languages in the linguistic landscape also has a symbolic function mainly when language is a salient dimension of a linguistic group. According to Bourhis (1997: 27) the use of a specific language can 'contribute most directly to the positive social identity of ethnolinguistic groups'. For 
example, the use of Basque in bilingual signs in Donostia is not only informative, because everybody can get the information in Spanish, but it has an important symbolic function which is related to affective factors and the feeling of Basque as a symbol of identity.

On the other hand, the use of English in commercial signs could be interpreted as informational mainly for foreign visitors but it is obvious that its increasing presence has a strong symbolic function for the local population as well in both Friesland and the Basque Country. Using English can be perceived as more prestigious and modern than using the local languages (see also Piller, 2001, 2003) but it can have important consequences for the future of the other languages present (see Ammon et al., 1994; Phillipson, 2003).

This study is limited to the analysis of linguistic signs in only two streets but shows the important role of the linguistic landscape and its relationship to linguistic policy in multilingual contexts. The linguistic landscape can provide a different perspective when analysing the sociolinguistic situation (Williams \& Van der Merwe, 1996: 56). The linguistic landscape does not necessarily reflect the use of the languages in oral communication but it provides information about written communication between language users.

\section{Correspondence}

Any correspondence should be directed to Prof. Jasone Cenoz, University of the Basque Country, Julianategi, Arriola 2, Donostia-San Sebastian 20018, Spain (jasone.cenoz@vc.ehu.es).

\section{References}

Ammon, U., Mattheier, K.J. and Nelde, P.H. (1994) English only? In Europe. Sociolinguistica 8 (Special Issue).

Ben-Rafael, E., Shohamy, E., Amara, M.H. and Trumper-Hecht, N. (2001) Linguistic landscape and multiculturalism: A Jewish-Arab comparative study. Unpublished research report.

Bhatia, T.K. (1992) Discourse functions and pragmatics of mixing: Advertising across cultures. World Englishes 11, 195-215.

Cenoz, J. (2001) Basque in Spain and France. In G. Extra and D. Gorter (eds) The Other Languages of Europe (pp. 45-57). Clevedon: Multilingual Matters.

Cenoz, J. (2005) English in bilingual programs in the Basque Country. International Journal of the Sociology of Language 171, 41-56.

Cenoz, J. and Jessner, U. (eds) (2000) English in Europe: The Acquisition of a Third Language. Clevedon: Multilingual Matters.

Eurobarometer (2001) Eurobarometer 54 Special - Europeans and languages. Brussels: INRA (Europe). On WWW at http://europa.eu.int/comm/education/policies/ lang/languages/ barolang_en.pdf. Accessed 21.12.04.

Euskararen Jarraipena III. La Continuidad del Euskera III. La Continuité de la Langue Basque II (2003) Vitoria-Gasteiz: Eusko Jaurlaritza.

Gorter, D. (2001) A Frisian update of reversing language shift. In J.A. Fishman (ed.) Can Threatened Languages be Saved? Reversing Language Shift: A 21 st Century Perspective (pp. 215-233). Clevedon: Multilingual Matters.

Gorter, D. (2005) Three languages of instruction in Fryslân. International Journal of the Sociology of Language 171, 57-74.

Gorter, D. and Jonkman, R.J. (1995) Taal yn Fryslân op 'e nij besjoen. LjouwertLeeuwarden: Fryske Akademy. 
Gorter, D., Riemersma, A.M.J. and Ytsma, J. (2001) Frisian in the Netherlands. In G. Extra and D. Gorter (eds) The Other Languages of Europe (Demographic, Sociolinguistic and Educational Perspectives) (pp. 103-118). Clevedon: Multilingual Matters.

Landry, R. and Bourhis, R.Y. (1997) Linguistic landscape and ethnolinguistic vitality: An empirical study. Journal of Language and Social Psychology 16 (1), 23-49.

Martin, E. (2002) Mixing English in French advertising. World Englishes 21, 375-401.

Phillipson, R. (2003) English-only Europe? Challenging Language Policy. London: Routledge.

Piller, I. (2001) Identity constructions in multilingual advertising. Language in Society 30, $153-186$.

Piller, I. (2003) Advertising as a site of language contact. Annual Review of Applied Linguistics 23, 170-183.

Ramamoorthy, L. (2002) Linguistic landscaping and reminiscences of French legacy: The case of Pondicherry. In N.H. Itagy and S.K. Singh (eds) Linguistic Landscaping in India (pp. 118-131). Mysore: Central Institute of Indian Languages/Mahatma Gandhi International Hindi University.

Rosenbaum, Y., Nadel, E., Cooper, R.L. and Fishman, J. (1977) English on Keren Kayemet Street. In J.A. Fishman, R.L. Cooper and A.W. Conrad (eds) The Spread of English (pp. 179-196). Rowley, MA: Newbury House.

Takashi, K. (1990) A sociolinguistic analysis of English borrowings in Japanese advertising texts. World Englishes 9, 327-341.

Williams, C.H. and Van der Merwe, I. (1996) Mapping the multilingual city: A research agenda for urban geolinguistics. Journal of Multilingual and Multicultural Development $17,49-65$.

Xiao, H. (1998) Minority languages in Dehong, China: Policy and reality. Journal of Multilingual and Multicultural Development 19, 221-235. 